\title{
High saturated fat and low carbohydrate diet decreases lifespan independent of body weight in mice
}

\author{
Alexandre Pastoris Muller ${ }^{1,2^{*}}$, Marcelo de Oliveira Dietrich ${ }^{1,2,3}$, Adriano Martimbianco de Assis ${ }^{1,2}$, \\ Diogo Onofre Souza ${ }^{1,2}$ and Luis Valmor Portela $a^{1,2}$
}

\begin{abstract}
Background: Obesity is a health problem that is reaching epidemic proportions worldwide. We investigated the effects of a life-long high saturated fat and low carbohydrate (HF) diet on the body mass, glucose tolerance, cognitive performance and lifespan of mice.

Findings: C57BL/6J mice were fed with a HF diet (60\% kcal/fat) or control diets (15\% kcal/fat) for 27 months. One-half of the mice on the HF diet developed obesity (diet-induced obese (DIO) mice), whereas the remaining mice were diet resistant (DR). At 8 months of age, both DIO and DR groups had increased hyperglycemic response during a glucose tolerance test, which was normalized in 16-month-old mice. At this latter time point, all groups presented similar performance in cognitive tests (Morris water maze and inhibitory avoidance). The survival curves of the HF and control diet groups started to diverge at 15 months of age and, after 27 months, the survival rate of mice in the DIO and DR groups was 40\%, whereas in the control diet group it was $75 \%$.
\end{abstract}

Conclusions: AHFdiet decreased the survival of mice independent of bodyweight.

Keywords: Obesity, Glucose tolerance, High-fat diet, Memory, Survival

\section{Findings}

High-fat diet decreases survival

Obesity and overweight are associated with numerous co-morbidities, including type 2 diabetes and neuropsychiatric disorders [1-3]. A sedentary lifestyle and excessive consumption of diets enriched in saturated fat and/or high glucose contribute to the onset and progression of these co-morbidities [4,5] leading to decreased life expectancy [6,7]. The effects of increased ingestion of dietary fat and carbohydrate are well stabilized in rodent models, leading to obesity and disturbed glucose metabolism, similar to that seen in humans [8-10].

The ingestion of high-fat diets, rich in saturated fat, lead to metabolic and neurochemical alterations, which

\footnotetext{
* Correspondence: alexandrep.muller@gmail.com

'Departamento de Bioquímica, ICBS, Universidade Federal do Rio Grande do Sul, Ramiro Barcelos, 2600 - Anexo I, Porto Alegre, RS 90035-000, Brazil ${ }^{2}$ Programa de Pós-graduaçãoemBioquímica, ICBS, Universidade Federal do Rio Grande do Sul, Ramiro Barcelos, 2600 - Anexo I, Porto Alegre RS 90035-000, Brazil

Full list of author information is available at the end of the article
}

contribute to impaired performance of rodents in a variety of behavioral tasks $[8,11]$. Both peripheral and central perturbations, including hyperglycemia, altered expression of synaptic proteins and signaling proteins, are among the changes implicated in the deterioration of the cognitive function [6].

One rodent strain that is particularly susceptible to the effects of dietary fat is the C57BL/6 mouse [12]. C57BL/6 mice develop severe obesity, hyperglycemia and hyperinsulinemia when fed a high-fat diet. However, when fat content is within the normal range animals remain lean and euglycemic [13]. Interestingly, about $50 \%$ of C57BL/ 6 mice do not become obese when fed with high-calorie diets $[12,13]$ indicating individual differences in terms of bodyweight gain under such dietary conditions despite similar environment and congenic genetic background $[14,15]$.

In the present study, we aimed to identify changes associated with consumption of alife-long high saturated fat and low carbohydrate (HF) diet on glucose tolerance, 
memory performance and life expectancy in C57BL/6 mice, comparing those mice that developed obesity (diet-induced obesity, DIO) to those that were resistant to obesity (diet resistant; DR).

\section{Availability of supporting data Animals and diet}

Twenty-five C57Bl6 male mice, aged 21 days, were randomly placed on one of two different diets for 27 months: a control diet $(\mathrm{CD}, \mathrm{n}=12)$ or aHFdiet $(\mathrm{n}=13)$. The HF diet contained 60\% energy from saturated and unsaturated fat (45\% lard and $15 \%$ soybean oil), $15 \%$ energy from starch (corn) and 25\% from protein (soybean protein). CD contained 15\% energy from saturated fat and unsaturated fat (soybean oil), 60\% energy from starch (corn) and 25\% from protein (soybean protein). Both diets were formulated in our laboratory and contained standard vitamins and minerals mixed with all essentials nutrients. Diets in the form of pellets and water were provided ad libitum [7]. Animals were weighedevery week during treatment. Mice were housed in standard cages $(20 \times 15 \mathrm{~cm})$, four animals per cage, in a room with a controlled temperature $\left(22^{\circ} \mathrm{C}\right)$ under a 12-hour light/12-hour dark cycle. All experiments were in agreement with the Committee on Care and Use of Experimental Animal Resources, Universidade Federal do Rio Grande do Sul, Brazil.

\section{Glucose tolerance test}

At 8 and 16 months of age, mice were fasted for 12 hours and then received an intraperitoneal (i.p.) injection of glucose ( $2 \mathrm{mg} / \mathrm{g}$ body weight). Blood was drawn from the tail and glucose levels was measured by a glucosimeter at time 0 (fasting) and at 30, 60 and 120 minutes post-glucose injection (AccuChek Active, Roche Diagnostics ${ }^{\circ}$ USA).

\section{Morris water maze task}

At 15 months of age, mice were subjected to a spatial memory task as previously described [16]. The water maze apparatus was a black circular pool $(110 \mathrm{~cm}$ diameter) with the water temperature maintained at $21 \pm 1^{\circ} \mathrm{C}$. Mice were trained with two trials per day for 5 consecutive days, each trial lasting up to 60 seconds with 20 seconds of rest on a hidden black platform. During training, mice learned to escape from the water by finding a hidden rigid black platform submerged approximately $1 \mathrm{~cm}$ below the water surface in a fixed location and, if it failed to find the platform in 60 seconds, it was placed gently on the platform and allowed to rest for $20 \mathrm{sec}-$ onds. The maze was located in a well-lit white room with several visual stimuli hanging on the walls to provide spatial cues. Decreased time latency to escape during each trial was measured as an indicator of learning.
On the sixth day, a probe trial was performed without the platform and the time spent in the target quadrant was used as a measure of retention memory.

\section{Inhibitory avoidance task}

At 15 months of age, mice were also submitted to an aversive memory task. The apparatus was a $50 \times 25 \times 25$ $\mathrm{cm}$ acrylic box with a floor of parallel caliber stainless steel bars (1 $\mathrm{mm}$ diameter) spaced $1 \mathrm{~cm}$ apart (Insight Equipamentos, SP, Brazil). Mice were placed on the platform located in the center of the apparatus and their latencies to step down on the floor with all four paws were measured with an automated device. During the training sessions, when animals stepped down onto the grid, they received a 1-second, 0.4-mA foot shock and were immediately returned to their home cages. The test sessions were performed without foot shock at 2 and 24 hours after training to evaluate short- and long-term memory, respectively. The mice were returned to the platform and the latency to step down (180 seconds maximum) was used as a measure of retention [17]. A foot shock was omitted during testing sessions. Data from the inhibitory avoidance task are shown as median (interquartile ranges) of latencies to step down on the grid in both the test and training sessions.

\section{Statistical analysis}

Results are expressed as means \pm S.E.M. except for data from the inhibitory avoidance task, which is represented by median and interquartile range. The data from the water maze acquisitions task, glucose tolerance test (GTT) and bodyweight were analyzed using a repeatedmeasures analysis of variance (ANOVA), followed by Duncan's post-hoc test. Data from the inhibitory avoidance task were analyzed by a Mann-Whitney $U$ test. Differences between groups were considered statistically significant at $P<0.05$. Cumulative survival probability was plotted on a Kaplan-Meier curve with pairwise comparisons of diets using the log-rank statistic analysis.

\section{Bodyweight}

As previously described by others [12,13], approximately $50 \%$ of the mice fed a HF diet became obese, whereas the other $50 \%$ had similar bodyweight compared to aged-matched control animals fed a control diet (Figure 1A). Based on this data set, we stratified animals fed a HF diet intoDR or DIO groups. Mice in the CD and DR groups increased bodyweight for up to 9 months, which was maintained up to 21 months of age. DIO mice still increased body weight for up to 15 months of age, and then this declined to reach the weight of the $\mathrm{CD}$ and $\mathrm{DR}$ groups at 18 months. The body weight of DIO mice was statistically different from other groups from 6 to 15 months $(P<0.05$, Figure $1 \mathrm{~A})$. 

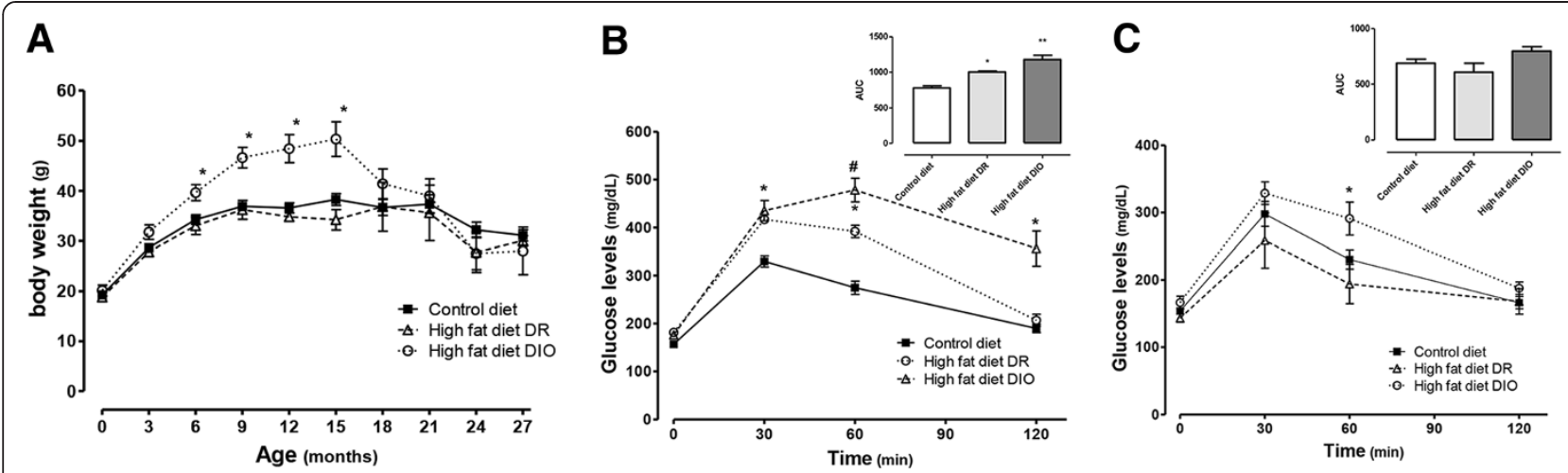

Figure 1 Body weight curves and glucose tolerance test. (A) Body weight curves (means \pm S.E.M.) during the length of the study $(* P<0.05$, $\mathrm{DIO}>\mathrm{DR}$ and $\mathrm{CD})$. The glucose tolerance test (GTT) was performed (B) at 8 months ( ${ }^{*} P<0.05, \mathrm{DIO}$ and $\mathrm{DR}>\mathrm{CD} ; \# P<0.05, \mathrm{DIO}>\mathrm{DR}$ and $\left.\mathrm{CD}\right)$ and (C) 15 months after diet introduction ( ${ }^{*} P<0.05, \mathrm{DIO}>\mathrm{DR}$ and $\mathrm{CD} ; \mathrm{CD}, \mathrm{n}=12$; high saturated fat and low carbohydratediet: $\mathrm{DIO}, \mathrm{n}=7 ; \mathrm{DR}, \mathrm{n}=6$ ). Blood glucose levels (means \pm S.E.M.) were assessed at fasting (0 minutes), 30, 60 and 120 minutes after an intraperitoneal glucose injection. Insert: area under the curve (AUC) of the GTT.CD, control diet; DIO, diet-induced obese; DR, diet resistant.

\section{Glucose tolerance test}

Next, we assessed glucose tolerance after 8 and 16 months of diet treatment. After 8 months of HF, both DIO and DR mice had increased fasting blood glucose levels (DR and DIO > CD, $P<0.05$ ) and a robust hyperglycemic response during GTT relative to $\mathrm{CD}$ (DR and $\mathrm{DIO}>\mathrm{CD}, P<0.05)$. In addition, DIO mice had longlasting hyperglycemia compared to $\mathrm{CD}$ and $\mathrm{DR}$ groups (120 minutes DIO > CD and DR, $P<0.05$, Figure $1 \mathrm{~B}$ ). $\mathrm{DR}$ and DIO had increased area under the curve of GTT $(\mathrm{DIO}>\mathrm{DR}>\mathrm{CD}, \mathrm{P}<0.05$; Figure $1 \mathrm{~B}$ insert). After 16 months on diet, the glucose profile during GTT was attenuated: DIO mice showed an impaired GTT response only at 60 minutes post i.p. glucose administration $(P<0.05$, Figure $1 C)$, and the area under the curve was not statistically different among groups (Figure $1 \mathrm{C}$, insert).

\section{Cognition tasks}

Spatial (Morris water maze; MWM) and aversive (inhibitory avoidance) memory was evaluated in 14- to 15month-old mice. In the MWM task, there was no significant effect of HF diet on latency to find the platform during the acquisition phase and probe trial (Figure 2A,B). In the inhibitory avoidance task, all groups showed an increased latency to step down the platform in the training and test sessions $(P<0.05$, Figure $2 \mathrm{C}$ ) with no differences among groups.

\section{Survival}

At 15 months of age, the survival curves of the HF groups and the $\mathrm{CD}$ group started to diverge and remained separate until the end of treatment (Figure 3A). At 27 months of age, the treatment was stopped. The survival rate of HF mice (DIO and DR) was $40 \%$ and that of the control diet mice was $75 \%$. There was no statistical difference in the survival rate between the DIO and DR mice (Figure 3B).

The present study demonstrate that mice fed a HF diet develop different phenotypes with regards to body weight (DIO and DR) and glucose tolerance (impaired at 8 months and almost normal at 16 months), but showed similar performance in memory tasks (spatial and aversive) and mortality rate. Moreover, the increasing mortality rate was dependent on dietary saturated fat composition but independent of body weight gain.

As previously shown by others [14,15], we observed that C57BL/6 mice fed a HF diet were either DR or DIO related to body weight gain. The body weight gain observed in DIO mice increased until mice were 15 months old, similarly to Baur et al. [18]. However, the normal age-associated body weight decline was greater in our study and preceded those reported by Baur et al. [18].

Obesity is a key factor involved in the pathology of diabetes and a risk factor to cardiovascular and cerebrovascular diseases. Mice fed with HF diets up to 8 months were more resistant to a glucose load compared to CDtreated mice. Blood glucose levels were elevated in DIO mice during the whole course of the GTT, whereas DR mice had increased glucose levels at fasting, 30 and 60 minutes during the GTT compared to CD mice, despite their lean phenotype. At 16 months age, animals appear to recover their ability to regulate peripheral glucose levels; however, at this time-point we cannot rule out an effect of age in glucose metabolism [19]. Moreover, subtle alterations can take place in the early stages of high saturated fat intake and can progress throughout the course of years, modifying insulin levels and carbohydrate metabolism or insulin receptor response, thus affecting peripheral tissues and brain metabolism.

A variety of studies have assumed that excessive HF consumption causes obesity and contributes to disturbances 


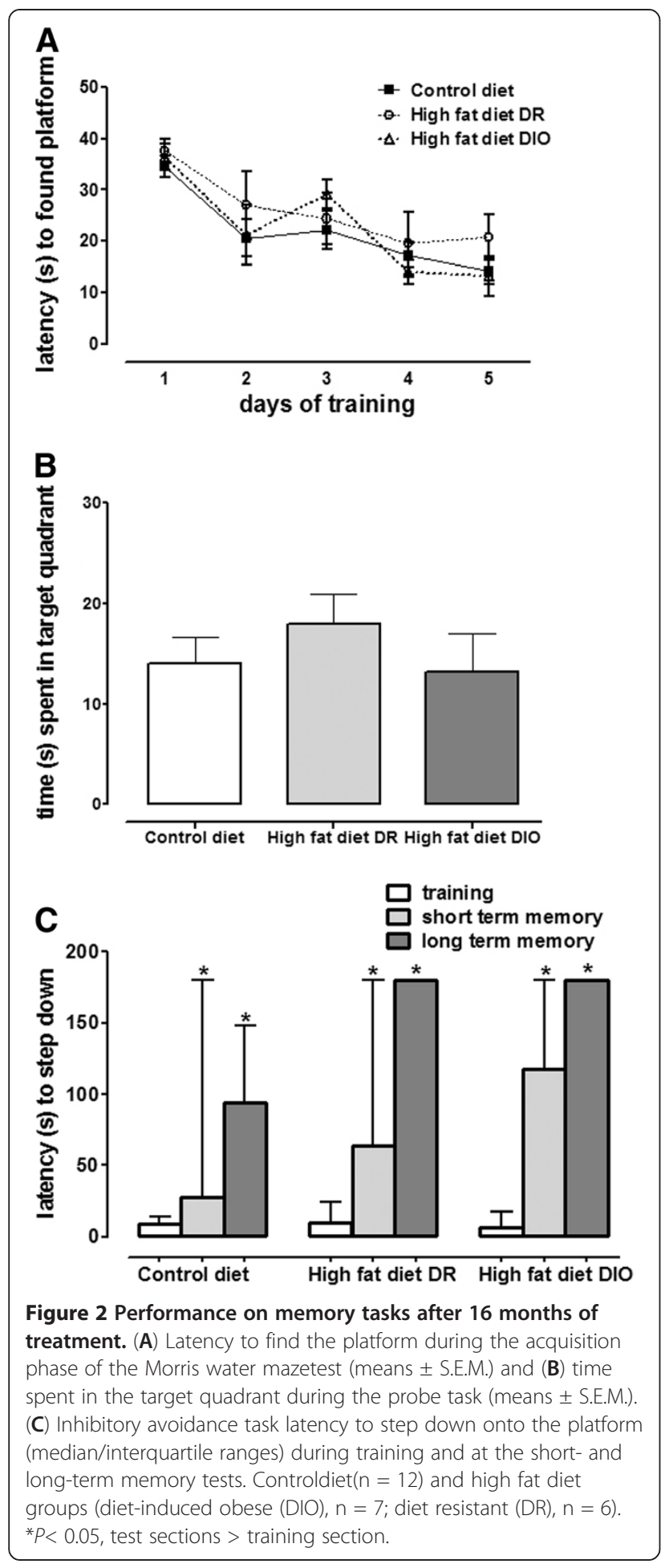

in synaptic machinery, with deleterious consequences for neuronal signaling, neuron-to-glia connectivity and cognitive functions $[11,20]$. Despite increased body weight at the time of behavioral tasks along with impaired glucose metabolism at earlier phases of HF, surprisingly DIO and DR mice showed no cognitive decline in spatial or aversive

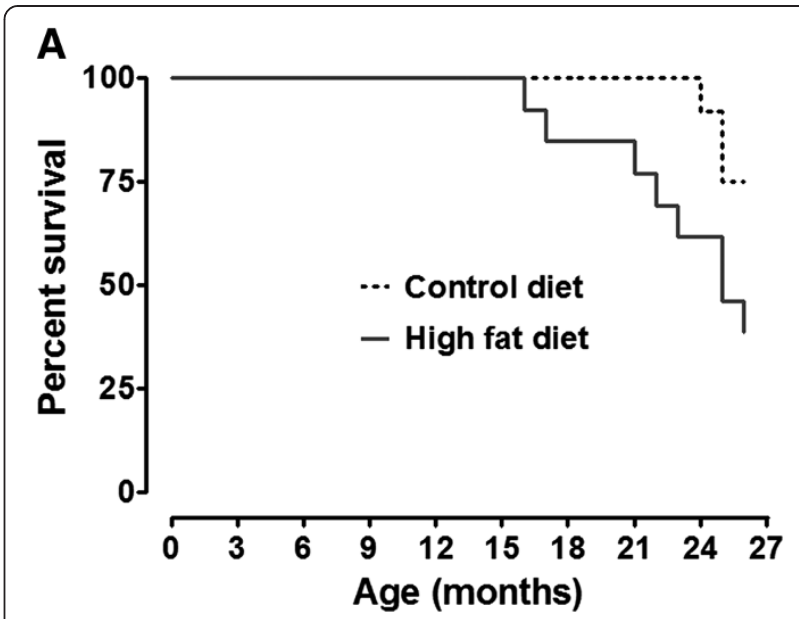

B

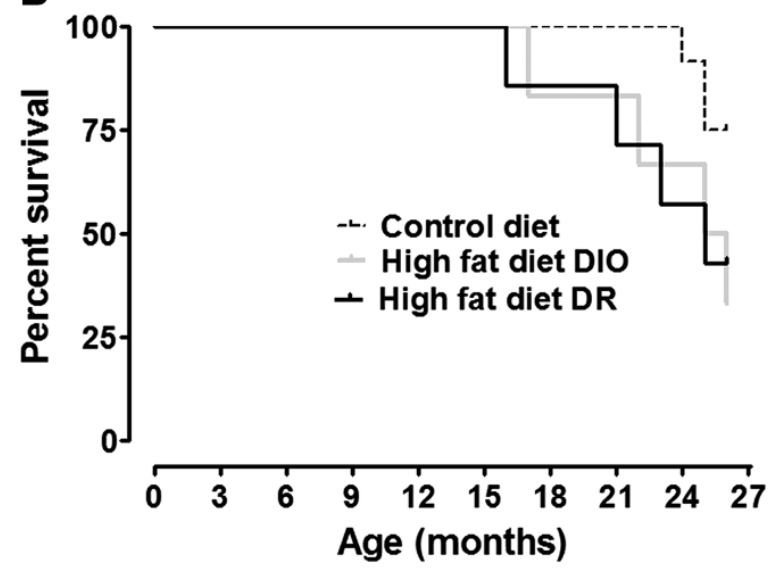

Figure 3 Kaplan-Meier survival curves over 27 months. (A) Survival based on treatment. Control diet (initial $n=12$; final $n=9$ ) and high fat diet (initial $n=13$; final $n=5$ ). (B) Survival based on phenotype (initial diet-induced obese (DIO), $n=7$; final $n=2$; initial diet resistant (DR), $n=6$; final $n=3$ ).

memory tasks compared to CD mice. Differences in time of regimen, diet composition, strain of animals and behavioral protocols may potentially account for these disparities. Moreover, considering that a HF diet-induced hyperglycemia during the early stages of treatment may cause synaptic alterations we cannot rule out memory deficits after 15 month of age

In addition to investigating the detrimental effects of a HF diet on cognitive function, we also examined its implication on lifespan. Although the association of obesity with increased risk of cardiovascular disease and diabetes is well known, it is often under-appreciated that the risks of other age-related diseases, such as cancer and inflammatory disorders, are also increased. Conversely, reducing caloric intake by $40 \%$ below that of ad libitum-fed animals (caloric restriction) is the most robust and reproducible way to delay age-related diseases and extend lifespan in mammals [21]. In this work, we 
demonstrated that mice fed with a HF diet for 27 months, ad libitum, had a decreased life expectancy and further, when this group was stratified into DIO and DR groups, the life expectancy curve was similar. Similarly, Baur et al. [18] reported that a high calorie diet $(60 \%$ from fat) caused a deleterious impact on general health status and survival rate in middle-aged mice. We were not able to explain the exact mechanism by which a HF diet increased mortality; however, the high energy source from saturated fat over 27 months could be implicated in increased reactive oxygen species production and oxidative stress, which is the main process responsible for aging and also a contributory factor for neurodegeneration [22,23]. Also, activation of inflammatory and immunological response induced by a HF diet and/or aging may exert a negative impact and be implicated in the differences in life expectancy observed in our study $[21,24,25]$.

In conclusion, C57BL/6 mice fed a HF diet may develop an obese phenotype or not compared to mice fed a CD. A HF diet decreased the survival rate independent of body weight gain.

\section{Abbreviations}

ANOVA: Analysis of variance; CD: Control diet; DIO: Diet-induced obese: DR: Diet resistant; GTT: Glucose tolerance test; HF: High saturated fat and low carbohydrate; i.p: Intraperitoneal; MWM: Morris water maze.

\section{Competing interests}

The authors declare that they have no competing interests.

\section{Authors' contributions}

APM: Performed experiments, analyzed data and wrote the manuscript. MOD: Analyzed data and wrote the manuscript. AMA: Performed experiments and analyzed data. DOS: analyzed data and wrote the manuscript; LVP: analyzed data and wrote the manuscript. All authors read and approved the final manuscript.

\section{Acknowledgements}

This work was supported by Brasil-Swiss Program 550011/2010-3 and INCTen -Excitoxicity and Neuroprotection, CNPq 573577/2008-5.

\section{Author details}

'Departamento de Bioquímica, ICBS, Universidade Federal do Rio Grande do Sul, Ramiro Barcelos, 2600 - Anexo I, Porto Alegre, RS 90035-000, Brazil. ${ }^{2}$ Programa de Pós-graduaçãoemBioquímica, ICBS, Universidade Federal do Rio Grande do Sul, Ramiro Barcelos, 2600 - Anexo I, Porto Alegre, RS 90035-000, Brazil. ${ }^{3}$ Program in Integrative Cell Signaling and Neurobiology of Metabolism, Section of Comparative Medicine, Yale University School of Medicine, New Haven, CT 06520, USA.

Received: 20 December 2012 Accepted: 5 April 2013

Published: 3 June 2013

\section{References}

1. Seidell JC: Obesity, insulin resistance and diabetes-a worldwide epidemic. Br J Nutr 2000, 83(Suppl 1):S5-S8.

2. Li Z, Bowerman S, Heber D: Health ramifications of the obesity epidemic SurgClin North Am 2005, 85:681-701. v.

3. Elias MF, Elias PK, Sullivan LM, Wolf PA, D'Agostino RB: Lower cognitive function in the presence of obesity and hypertension: the Framingham heart study. Int J ObesRelatMetabDisord 2003, 27:260-268.

4. Bray GA, Popkin BM: Dietary fat intake does affect obesity! Am J ClinNutr 1998, 68:1157-1173.
5. Heber D: An integrative view of obesity. Am J ClinNutr 2010, 91:280S-283S.

6. Stranahan AM, Norman ED, Lee K, Cutler RG, Telljohann RS, Egan JM, Mattson MP: Diet-induced insulin resistance impairs hippocampal synaptic plasticity and cognition in middle-aged rats. Hippocampus 2008, 18:1085-1088.

7. Muller AP, Cammarota M, de Oliveira Dietrich M, Rotta LN, Portela LV, Souza DO, Izquierdo I, Bevilaqua LR, Perry ML: Different effect of high fat diet and physical exercise in the hippocampal signaling. Neurochem Res 2008, 33:880-885.

8. Molteni R, Wu A, Vaynman S, Ying Z, Barnard RJ, Gomez-Pinilla F: Exercise reverses the harmful effects of consumption of a high-fat diet on synaptic and behavioral plasticity associated to the action of brain-derived neurotrophic factor. Neuroscience 2004, 123:429-440.

9. Petro AE, Cotter J, Cooper DA, Peters JC, Surwit SJ, Surwit RS: Fat, carbohydrate, and calories in the development of diabetes and obesity in the C57BL/6J mouse. Metabolism 2004, 53:454-457.

10. Parekh PI, Petro AE, Tiller JM, Feinglos MN, Surwit RS: Reversal of diet-induced obesity and diabetes in C57BL/6J mice. Metabolism 1998, 47:1089-1096.

11. Farr SA, Yamada KA, Butterfield DA, Abdul HM, Xu L, Miller NE, Banks WA, Morley JE: Obesity and hypertriglyceridemia produce cognitive impairment. Endocrinology 2008, 149:2628-2636.

12. Surwit RS, Kuhn CM, Cochrane C, McCubbin JA, Feinglos MN: Diet-induced type II diabetes in C57BL/6J mice. Diabetes 1988, 37:1163-1167.

13. Surwit RS, Feinglos MN, Rodin J, Sutherland A, Petro AE, Opara EC, Kuhn CM, Rebuffe-Scrive M: Differential effects of fat and sucrose on the development of obesity and diabetes in C57BL/6J and A/J mice. Metabolism 1995, 44:645-651.

14. Huang XF, Han M, Storlien LH: The level of NPY receptor mRNA expression in diet-induced obese and resistant mice. Brain Res Mol Brain Res 2003, 115:21-28.

15. Levin BE, Keesey RE: Defense of differing body weight set points in dietinduced obese and resistant rats. Am J Physiol 1998, 274:R412-R419.

16. Muller AP, Zimmer ER, Kalinine E, Haas CB, Oses JP, Martimbianco de Assis A, Galina A, Souza DO, Portela LV: Physical exercise exacerbates memory deficits induced by intracerebroventricular STZ but improves insulin regulation of $\mathrm{H} 2 \mathrm{O} 2$ production in mice synaptosomes. J Alzheimers Dis 2012, 30:889-898.

17. Muller AP, Gnoatto J, Moreira JD, Zimmer ER, Haas CB, Lulhier F, Perry ML, Souza DO, Torres-Aleman I, Portela LV: Exercise increases insulin signaling in the hippocampus: physiological effects and pharmacological impact of intracerebroventricular insulin administration in mice. Hippocampus 2011, 21:1082-1092.

18. Baur JA, Pearson KJ, Price NL, Jamieson HA, Lerin C, Kalra A, Prabhu W, Allard JS, Lopez-Lluch G, Lewis K, Pistell PJ, Poosala S, Becker KG, Boss O, Gwinn D, Wang M, Ramaswamy S, Fishbein KW, Spencer RG, Lakatta EG, Le Couteur D, Shaw RJ, Navas P, Puigserver P, Ingram DK, de Cabo R, Sinclair DA: Resveratrol improves health and survival of mice on a high-calorie diet. Nature 2006, 444:337-342

19. Mielke JG, Nicolitch K, Avellaneda V, Earlam K, Ahuja T, Mealing G, Messier C: Longitudinal study of the effects of a high-fat diet on glucose regulation, hippocampal function, and cerebral insulin sensitivity in C57BL/6 mice. Behav Brain Res 2006, 175:374-382.

20. Schwartz MW, Porte D Jr: Diabetes, obesity, and the brain. Science 2005, 307:375-379.

21. Blackwell BN, Bucci TJ, Hart RW, Turturro A: Longevity, body weight, and neoplasia in ad libitum-fed and diet-restricted C57BL6 mice fed NIH-31 open formula diet. ToxicolPathol 1995, 23:570-582.

22. Dumont M, Beal MF: Neuroprotective strategies involving ROS in Alzheimer disease. Free RadicBiol Med 2011, 51:1014-1026.

23. Selman C, Blount JD, Nussey DH, Speakman JR: Oxidative damage, ageing, and life-history evolution: where now? Trends EcolEvol 2012, 27:570-577.

24. Skibola CF: Obesity, diet and risk of non-Hodgkin lymphoma. Cancer Epidemiol Biomarkers Prev 2007, 16:392-395.

25. Zheng T, Holford TR, Leaderer B, Zhang Y, Zahm SH, Flynn S, Tallini G, Zhang $\mathrm{B}$, Zhou $\mathrm{K}$, Owens $\mathrm{PH}$, et al: Diet and nutrient intakes and risk of non-Hodgkin's lymphoma in Connecticut women. Am J Epidemiol 2004, 159:454-466.

doi:10.1186/2046-2395-2-10

Cite this article as: Muller et al:: High saturated fat and low carbohydrate diet decreases lifespan independent of body weight in mice. Longevity \& Healthspan 2013 2:10 